\title{
REASONS FOR RESUBMISSION OF RESEARCH PROJECTS TO THE RESEARCH ETHICS COMMITTEE OF A UNIVERSITY HOSPITAL IN SÃO PAULO, BRAZIL
}

\author{
Mariana Bueno, Maria Meimei Brevidelli, Thaís Cocarelli, Gianni Mara Silva \\ dos Santos, Maria Auxiliadora Ferraz, Décio Mion Jr.
}

doi: $10.1590 / \mathrm{S1807-59322009000900002}$

Bueno M, Brevidelli MM, Cocarelli T, Santos GMS dos, Ferraz MA, Mion Jr. D. Reasons for resubmission of research projects to the research Ethics Committee of a University Hospital in São Paulo, Brazil. Clinics. 2009;64(9):831-6.

INTRODUCTION: It is important to know the reasons for resubmitting research projects to the Research Ethics Committee in order to help researchers to prepare their research projects, informed consent forms and needed research documentation.

OBJECTIVES: To verify the reasons for resubmitting projects that were previously rejected by the Ethics Committee.

METHOD: This is a cross-sectional study that evaluated research projects involving human beings. Research projects were submitted in 2007 to the Research Ethics Committee of the Hospital das Clínicas, Faculdade de Medicina da Universidade de São Paulo. RESULTS: One thousand two hundred and fifty six research projects were submitted to the ethics committee and the average time for evaluating the research projects and related documents until a final decision was reached was 49.95 days. From the total, 399 projects were reviewed in 2 or more meetings until a final decision was reached. Of these, 392 research projects were included in the study; 35 projects were subsequently excluded for involving animals. Among the research projects included, $42.5 \%$ concerned research with new drugs, vaccines and diagnostic tests, $48.5 \%$ consisted of undergraduate students' research projects, $68.9 \%$ of the research had no sponsorship, and $97.5 \%$ were eventually approved. The main reasons for returning the projects to the researchers were the use of inadequate language and/or difficulty of understanding the informed consent form (32.2\%), lack of information about the protocol at the informed consent form (25.8\%), as well as doubts regarding methodological and statistical issues of the protocol (77.1\%). Other reasons for returning the research projects involved lack of, inaccuracy on or incomplete documentation, need of clarification or approval for participation of external entities on the research, lack of information on financial support.

CONCLUSION: Among the research projects that were returned to the researchers for additional clarification, the main reasons were inadequacies or doubts about the terms used in the informed consent form as well as lack of information regarding the research at the informed consent form and methodological and statistical issues regarding the protocol.

KEYWORDS: Ethics in research; Bioethics; Research ethics committee.

\section{INTRODUCTION}

The importance of ethical principles guiding research involving human beings have been evident since the Code of Nuremberg ${ }^{1}$ (1947), which was created with the intention of preventing the repetition of the atrocities committed in illegal experiments conducted by Nazi

Hospital das Clinicas, Faculdade de Medicina da Universidade São Paulo - São Paulo/SP, Brazil.

Email: maribueno@hotmail.com

Tel: 55113069.7686

Received for publication on July 08, 2009

Accepted for publication on August 17, 2009 physicians in concentration camp prisoners. Since then, several other national and international regulations, such as the Declaration of Helsinki ${ }^{2}$ (1964), the Belmont Report ${ }^{3}$ (1978) and the Resolution 196/96 (1996), provide guidance concerning ethical issues related to research involving human beings.

Currently, research involving human subjects must be reviewed and approved by a Research Ethics Committee (REC) before its start. The assessment by a REC is needed in order to guarantee respect to the autonomy of the research volunteers, as well as to guarantee beneficence, nonmaleficence and justice ${ }^{5}$. Thus, the RECs' main functions are to evaluate research projects based on their scientific 
relevance, technical and operational feasibility, in addition to reviewing ethics and morality of the research. ${ }^{6}$

At the Hospital das Clínicas, Faculdade de Medicina, Universidade de São Paulo (HCFMUSP), the projects are reviewed by the REC, named Comissão para Análise de Projetos de Pesquisa (CAPPesq), which consists of 59 members who meet every two weeks. In 2007, the committee reviewed 1,256 new research projects. Some of these projects were reviewed over the course of two or more meetings for several reasons, such as lack of documentation, incomplete information provided at forms, and problems with either the research project or the informed consent form (ICF). These issues compelled the researcher to resubmit the project with the necessary corrections, adjustments and inclusions, resulting in extension of deadlines and consequent delay in issuing the final decision by the CAPPesq.

In light of such obstacles in the research projects review processes, it is fundamentally important for the community of researchers linked to the institution to know the profile of the research proposals reviewed by the committee in two or more meetings as well as the main reasons why some research projects must be resubmitted for analyses. With access to this information, the professionals will be able to better prepare their research projects, as well as the documentation needed for the project to be properly submitted and, thus, speed up the review and the ethical approval procedures for such research projects.

Thus, the objectives of the study were:

- To characterize the research projects submitted for review to the REC with relation to subject area, academic purpose, specific thematic areas, sponsorship, number of meetings necessary to analyze the research project, deliberation and issuing of final opinion, and average time it takes for the final decision to be made.

- To identify the reasons why the research projects needed to be resubmitted for analysis to the REC.

\section{METHOD}

The study was conducted between May and June, 2008 at the HCFMUSP. This is a tertiary-level university hospital, located in the city of São Paulo. All research projects involving human subjects that were submitted to the CAPPesq during 2007 and that went through two or more reviews by this committee were included in this study. Research conducted on animals was excluded.

A set of documents are required by the CAPPesq in order to analyze research projects. For all research projects, the committee prepares a binder containing all the documentation submitted, such as an institutional registration form for the investigator and for the research project, outline of the research project, informed consent form (ICF), as well correspondences between the researchers and the committee and opinions of the REC.

The following data were collected: subject or field of research, research in special thematic areas, academic purpose, sponsorship, number of sessions needed for issuing the committee's final decision, time elapsed between the start of the process and the final decision and the number of sessions in which the research project was analyzed, reasons for returning documents to the researchers, and details of the reasons for subsequent resubmission of research projects to the CAPPesq. Specifically, with regard to the reasons for returning research documents, the data were extracted from the opinions given by the committee. Because these data are not described in a standardized manner, all data were fully transcribed and later categorized in an attempt to have homogenous results.

Data were stored in Excel 2000 for Windows. Statistical analyses were performed using Statistical Package for Social Sciences (SPSS, version 11.0) and Minitab (version 15.0). For the quantitative variables, summary measures of means and standard deviations ${ }^{7}$ were calculated. The qualitative variables were analyzed through the calculation of absolute and relative frequencies. ${ }^{7}$ This project was approved by the CAPPesq (0680/08).

\section{RESULTS}

In $2007,1,256$ projects were submitted to the CAPPesq for analysis. The average time for evaluating the research projects and related documents until a final decision was reached was 49.95 days. Most of the projects, 857 projects $(68 \%)$, were reviewed in a single meeting, and their average review time was 39 days.

Among the other projects, 342 (27.2\%) were reviewed in two meetings, in an average time of 68.78 days; 53 projects $(4.2 \%)$ were reviewed in three meetings, in an average time of 99.62 days; and 4 projects $(0.3 \%)$ went through four meetings in an average time of 127.30 days.

Of the 399 projects that were reviewed in two or more sessions, 392 binders were retrieved and included in this study. The rest were unavailable during data collection period since they were being analyzed by the reviewers. From the 392 projects, 357 (91.1\%) referred to research involving human subjects and 35 (8.9\%) involved animal studies, thus were excluded from this study.

Table 1 shows the areas of research, as registered by the researchers themselves in a specific CAPPesq form.

This table shows that Cardiology/Pulmonology had the highest number of projects submitted $(45,12.6 \%)$, followed 
Table 1 - Research areas

\begin{tabular}{lcc}
\hline Research areas & $\mathbf{N}$ & $\mathbf{\%}$ \\
\hline Cardiology/Pulmonology & 45 & 12.6 \\
General Medicine & 35 & 9.8 \\
Psychiatry/Psychology & 26 & 7.3 \\
Gynecology/Obstetrics & 25 & 7.0 \\
Ophthalmology/Otorhinolaryingology & 25 & 7.0 \\
Surgery & 23 & 6.5 \\
Neurology & 23 & 6.5 \\
Pediatrics & 21 & 5.9 \\
Physiotherapy/Phonoaudiology/Occupational & 19 & 5.3 \\
Therapy & & \\
Gastroenterology & 18 & 5.1 \\
Radiology/Radiotherapy & 15 & 4.2 \\
Orthopedics/Traumatology & 14 & 3.9 \\
Pathology & 14 & 3.9 \\
Dermatology & 09 & 2.5 \\
Infectious and Parasitic Diseases & 08 & 2.2 \\
Preventive Medicine & 07 & 2.0 \\
Others & 30 & 8.4 \\
\hline TOTAL & $\mathbf{3 5 7}$ & $\mathbf{1 0 0}$ \\
\hline
\end{tabular}

by General Medicine (35, 9.8\%), and Psychiatry (26, 7.3\%).

With regard to special thematic research, investigators considered 120 research projects related to special thematic areas: $51(42.5 \%)$ research projects were related to new drugs, vaccines and diagnostic tests, 26 (21.7\%) were related to new procedures, and 23 (19.2\%) were related to human genetics. The classification of the research project as special thematic areas is determined by the researcher at the time the specific CAPPesq form is completed (Table 2).

Concerning academic purpose, 173 (48.5\%) research projects were related to undergraduate students (predominantly those in scientific initiation modality), 156 (43.7\%) research projects were linked to graduate students (Master and $\mathrm{PhD}$ students), and 28 (7.8\%) studies had other purposes.

Table 2 - Research in special thematic areas

\begin{tabular}{lcc}
\hline Thematic areas & $\mathbf{N}$ & $\mathbf{\%}$ \\
\hline New drugs, vaccines and diagnostic tests & 51 & 42.5 \\
New procedures & 26 & 21.7 \\
Human genetics & 23 & 19.2 \\
Foreign participation & 12 & 10.0 \\
Biosecurity & 06 & 5.0 \\
Human reproduction & 02 & 1.7 \\
\hline TOTAL & $\mathbf{1 2 0}$ & $\mathbf{1 0 0}$ \\
\hline
\end{tabular}

One hundred and eleven researches (31.1\%) were sponsored by industry or governmental research funding agencies. The other projects were supported by the researchers.

Of the 357 projects that were included in this study, the vast majority (348 or $97.5 \%$ ) were approved. Five (1.4\%) projects were rejected, and four $(1.1 \%)$ were submitted to the commission only for committee awareness.

The reasons why the research projects were returned to the researchers for corrections, adjustments or clarifications and subsequent resubmitting to the CAPPesq are described next. Eight hundred reasons for project document return were listed, with an average of 2.2 reasons for each returned research project.

The two main reasons for returning projects to the researchers were problems with the ICF (422 (52.7\%) occurrences) and inadequacies at the research protocol (205 (25.6\%) occurrences). Both of these reasons represent $78.3 \%$ (627) of the reasons for returning research projects to the researchers. Other reported reasons for return were: incomplete or incorrect documentation (68 cases, 8.5\%), incomplete or incorrect registration form of the research and/or of the researcher $(65 ; 8.1 \%)$, absence of research execution schedule $(21 ; 2.6 \%)$, doubts regarding financial support $(15 ; 1.8 \%)$ and issues related to the cover page of the Comissão Nacional de Ética em Pesquisa (CONEP) (4; $0.5 \%)$

Details were listed for every reason of each project that was returned. Regarding the ICF (Table 3), main problems identified were the use of inadequate language and/or difficulty in understanding the ICF's content (136 cases, $32.2 \%)$. Insufficient information related to the protocol in the ICF $(109 ; 25.8 \%)$ was also reported. In four cases, it was not possible to identify the problems identified at the ICF.

In regard to the 205 project returned due to research protocol issues (Table 4), the main reason concerned doubts about methodology and/or statistics (158 cases, $77.1 \%$ ).

As for the documentation related to the project, the major issues were need for clarification about and/or agreement to the participation of external institutions $(24 ; 35.3 \%)$ such as diagnostic and imaging services, health services and educational institutions. There were also $11(16.2 \%)$ cases in which lack of researcher's or research team's documentation (such as curriculum vitae) (Table 5).

Pertaining to the registration forms of the researcher or the research project, the main problem that led to the return of research projects was incomplete/inaccurate data (32 cases, $49.2 \%$ ). In one case, it was not possible to determine the reason for the return. Regarding the research schedule, most problems were related to its absence or inadequacy $(14 ; 66.7 \%)$. Issues related to the study financing also caused 
Table 3 - Informed consent-related reasons for returning research projects to the researchers

\begin{tabular}{|c|c|c|}
\hline & $\mathbf{N}$ & $\%$ \\
\hline $\begin{array}{l}\text { Inadequate language and/or difficulty of } \\
\text { understanding }\end{array}$ & 136 & 32.2 \\
\hline Lack of information about the protocol & 109 & 25.8 \\
\hline Incomplete/inaccurate filling out form & 39 & 9.2 \\
\hline Lack of information on researcher contacts & 32 & 7.6 \\
\hline $\begin{array}{l}\text { Lack of or poor explanation about monetary } \\
\text { compensation }\end{array}$ & 28 & 6.6 \\
\hline $\begin{array}{l}\text { Doubts and/or divergence about research's risk } \\
\text { classification }\end{array}$ & 22 & 5.2 \\
\hline $\begin{array}{l}\text { No explanation whether participation in study is } \\
\text { voluntary }\end{array}$ & 14 & 3.3 \\
\hline Lack of or incomplete information on confidentiality & 9 & 2.1 \\
\hline $\begin{array}{l}\text { Lack of or incomplete information related to } \\
\text { treatment in case of occurrence of adverse events }\end{array}$ & 7 & 1.7 \\
\hline $\begin{array}{l}\text { Lack of or incomplete explanation of risks of } \\
\text { procedures involved in the study }\end{array}$ & 7 & 1.7 \\
\hline Divergence between protocol and informed consent & 6 & 1.4 \\
\hline Lack of or incomplete information of reimbursement & 4 & 0.9 \\
\hline Different versions submitted & 3 & 0.7 \\
\hline $\begin{array}{l}\text { Lack of or incomplete information about access to } \\
\text { medication at the end of the study }\end{array}$ & 2 & 0.5 \\
\hline Unidentified & 4 & 0.9 \\
\hline TOTAL & 422 & 100 \\
\hline
\end{tabular}

Table 4 - Protocol-related reasons for returning research projects to the researchers

\begin{tabular}{lcc}
\hline & $\mathbf{N}$ & $\mathbf{\%}$ \\
\hline Doubts about methodology and/or statistics & 158 & 77.1 \\
$\begin{array}{l}\text { Lack of or incomplete information regarding the } \\
\text { risks/benefits of the research }\end{array}$ & 16 & 7.8 \\
Lack/failure of justification for study & 11 & 5.4 \\
$\begin{array}{l}\text { Doubts about use of medication/placebo and/or } \\
\text { supply of medication after end of study }\end{array}$ & 5 & 2.4 \\
Incomplete protocol & 5 & 2.4 \\
Doubts related to foreign participation & 3 & 1.5 \\
Doubts related to ethical validity of research & 3 & 1.5 \\
Presentation of different versions & 2 & 1.0 \\
Doubts related to research volunteer compensation & 1 & 0.5 \\
Unidentified & 1 & 0.5 \\
\hline TOTAL & $\mathbf{2 0 5}$ & $\mathbf{1 0 0}$ \\
\hline
\end{tabular}

$15(4.2 \%)$ research projects to be returned, the main reason being absence of information on financial support (6 cases, $40.0 \%$ ). Improper filling out of the cover page (CONEP) resulted in the return of four (1.1\%) documents (Table 6).
Table 5 - Research project documentation-related reasons for research projects return to the researchers

\begin{tabular}{lcc}
\hline & N & \% \\
\hline $\begin{array}{l}\text { Clarification and/or letter of agreement needed of } \\
\text { participation of external entities }\end{array}$ & 24 & 35.3 \\
$\begin{array}{l}\text { Lack of documentation of the researcher and/or the } \\
\text { research team }\end{array}$ & 11 & 16.2 \\
$\begin{array}{l}\text { Failure to send documentation and/or CONEP } \\
\text { approval }\end{array}$ & 7 & 10.3 \\
$\begin{array}{l}\text { Lack of REC approval of the institution that } \\
\text { coordinates the research }\end{array}$ & 6 & 8.8 \\
$\begin{array}{l}\text { Lack of approval of the department in charge of the } \\
\text { study }\end{array}$ & 6 & 8.8 \\
$\begin{array}{l}\text { Lack of documentation referring to insurance/ } \\
\text { indemnity }\end{array}$ & 4 & 5.9 \\
$\begin{array}{l}\text { Divergent information in different documents } \\
\text { Clarification needed on medication registration }\end{array}$ & 3 & 4.4 \\
$\begin{array}{l}\text { Lack of confidentiality statement } \\
\text { Clarification needed on sending biological material } \\
\text { abroad }\end{array}$ & 1 & 2.9 \\
$\begin{array}{l}\text { Lack of documentation on transportation of } \\
\text { biological material }\end{array}$ & 1 & 1.5 \\
$\begin{array}{l}\text { Lack of documentation on previous studies } \\
\text { TOTAL }\end{array}$ & 1 & 1.5 \\
\hline
\end{tabular}

\section{DISCUSSION}

Several research projects and related documents submitted to the RECs for review show common errors that may be corrected in a quick and simple way, if appropriate attention is paid while preparing the research project as well as the necessary documentation. ${ }^{5}$

Moreover, investigators who are familiar with the relevant ethical information, which is generally debated in literature, show greater knowledge and give better arguments in discussions and negotiations with the REC in regard to the ethical analysis of their research projects. ${ }^{8}$

Data presented demonstrate that the issues raised by the CAPPesq usually involve the content of the ICF and/or methodological or statistical issues of the research project. Therefore, the researcher and his or her team must dedicate special attention to developing both.

ICF is currently considered to be the cornerstone of research ethics ${ }^{9}$ and, therefore, has become one of the main areas to which attention is paid in the ethical review of research projects. Moreover, mandatory signature of the ICF by the volunteer and by the researcher before the inclusion at the research may minimize the possibilities of including volunteers who are not aware about the study purposes and procedures or even who have not given consent to be included in a research. ${ }^{10}$ 
Table 6 - Other reasons for returning the research projects to the researchers related to registration of the researcher and/or the research, schedule, financing and cover page

\begin{tabular}{|c|c|c|}
\hline Registration & $\mathbf{N}$ & $\%$ \\
\hline Incomplete/inaccuracy of registration form & 32 & 49.2 \\
\hline Discrepant information on the research team & 15 & 23.1 \\
\hline $\begin{array}{l}\text { Clarification needed on link between researcher and } \\
\text { institution }\end{array}$ & 8 & 12.3 \\
\hline Discrepant information in different documents & 8 & 12.3 \\
\hline Unidentified & 2 & 3.1 \\
\hline TOTAL & 65 & 100 \\
\hline Schedule & $\mathbf{N}$ & $\%$ \\
\hline Lack/inaccuracy of execution schedule & 14 & 66.7 \\
\hline Beginning estimated prior to approval by CAPPesq & 7 & 33.3 \\
\hline TOTAL & 21 & 100 \\
\hline Financing & $\mathbf{N}$ & $\%$ \\
\hline No mention of financial support & 6 & 40.0 \\
\hline Clarification on items to be financed & 4 & 26.7 \\
\hline Lack of details on type of financial support & 2 & 13.3 \\
\hline $\begin{array}{l}\text { Discrepancies between amounts presented by } \\
\text { researcher and sponsor }\end{array}$ & 2 & 13.3 \\
\hline Clarification on budget management & 1 & 6.7 \\
\hline TOTAL & 15 & 100 \\
\hline Cover page & $\mathbf{N}$ & $\%$ \\
\hline Missing signatures & 2 & 50.0 \\
\hline Incorrect research area & 1 & 25.0 \\
\hline Discrepant information in different documents & 1 & 25.0 \\
\hline TOTAL & 04 & 100 \\
\hline
\end{tabular}

In this study, the major problem associated with ICF were the use of inadequate language and/or of difficulty in understanding the content of these forms. This is in agreement with other Brazilian studies. In one study, the analysis of 12 ICF indicated that the mean readability index was $41.8 \%$, and only one form had an adequate level of understanding. Moreover, the results indicated that the level of education needed for understanding $91.7 \%$ of ICF was 11 years of education. ${ }^{11}$ Another study evaluated 48 forms for research and medical procedures and results indicated that the level of education necessary for understanding the text was 16.4 years of education. ${ }^{12}$

One of the major responsibilities of the RECs is to ensure that the ICF is written in such a way that the research volunteer understands the research, especially the potential risks and benefits. ${ }^{5}$ The ICF content and language might be directed to the research volunteer. ${ }^{8}$ Thus, it is essential that the language used in the forms is adapted to the type of population that will be included in the study, which is the researcher's responsibility.
Poor information about the protocol in the ICFs was also a frequent reason for returning the research projects to the researchers. The ICF must contain information regarding background, justification and objectives of the study in addition to the procedures that will be carried out during the study. ${ }^{4}$ It ensures that the volunteer is aware of all the events and procedures to which he or she will be subjected during the research.

With regard to the protocol analysis, the scientific merit of the research project must be reviewed along with the ethical issues involved ${ }^{9}$. It is also necessary for the RECs to review the methods used in the research project. In addition, the need for obtaining previous ethical approval to develop studies involving human subjects actually motivates investigators to write research projects, ${ }^{10}$ instead of conducting researches without any protocol or previous planning.

The current study data indicate that the main protocol related reasons for returning research protocols are doubts about either study design or statistical planning. Comments accompanying returned protocols mainly address clarification of the type of study (retrospective or prospective), the need for better description of study procedures, justifications for sample size, and description of statistical tests to be used, among others.

Investigators must pay attention to the structure of the research project in order to enable the scientific and operational aspects of the study to be understood not only by review experts in that field of research, but also by reviewers from other research fields, and even reviewers who are not linked to the research but are members of the community. ${ }^{5}$

Items such as research schedule, detailed financial budget, and origin of available resources are also important pieces of information that should be described. ${ }^{4}$ If they are not duly attached to the research project, the RECs must request clarifications about such issues.

Concerning documentation, it is important to know which documents and forms must be filled out and sent to each specific committee. There are models and specific guidelines for the REC that must be followed by the researchers and their research teams, with the objective of adjusting the material to be sent and, thus, facilitating a speedy review and reducing procedure time.

The ethical analysis of research projects must be viewed as an important and fundamental step in conducting studies involving human subjects. The researchers' expectations related to the RECs' analysis may include learning, based on the considerations made by the REC in regard to the research project, and also may include potential benefits to their research. ${ }^{8}$ 


\section{CONCLUSION}

In 2007, the research projects analyzed by the CAPPesq took an average of 49.95 days to get through all the procedural steps.

Among the research projects involving human subjects that were submitted for two or more reviews by the CAPPesq, the majority, $12.6 \%$, belonged to Cardiology/ Pulmonology; $48.5 \%$ of the research involved undergraduate students; $42.6 \%$ of the research projects were related to new drugs, vaccines and diagnostic tests; $68.9 \%$ did not involve any sponsorship. The majority of the research projects were eventually approved $(97.5 \%)$.

The main reason for returning documents to the researchers for subsequent resubmission to the CAPPesq was issues with the ICF, specifically regarding inaccurate use of language and poor information related to the research protocol. The second most common reason for returning the documents to the researchers was inadequacy of the protocol itself.

\section{FINAL CONSIDERATIONS}

Based on the results obtained, this study will contribute to the appropriate preparation and structuring of research projects and related documents to be submitted to the REC.

The reasons presented for return reveal that, when the research projects are prepared, the researcher shows insufficient knowledge and pays little attention to the guidelines. The ethical and methodological issues reported by this study need to be considered by researchers, so the process of submission to the REC can cease to be a "painful ordeal", as it is currently considered, and can instead become a simple and quick procedure.

\section{ACKNOWLEDGEMENTS}

We are would like to acknowledge the support and collaboration of Prof. Dr. Eduardo Massad and Ms. Márcia Aparecida Teixeira de Carvalho.

\section{REFERENCES}

1. The Nuremberg Code (1947). BMJ. 1996;313:1448.

2. World Medical Association - Declaration of Helsinki. JAMA. 1997;277:925-6.

3. The National Commission for the Protection of Human Subjects of Biomedical and Behavioral Research. The Belmont Report: ethical principles and guidelines for the protection of human subjects of research. Washington: U.S. Department of Health, Education, and Welfare. 1979:1-8.

4. Brasil. Conselho Nacional de Saúde. Resolução 196/96 sobre pesquisa envolvendo seres humanos. Diário Oficial da União, Brasília, 16. p.21082-5.

5. Colt HG, Mulnard RA. Writing an application for a human subjects institutional review board. Chest. 2006;130:1605-7.

6. Schramm FR. Aspectos cognitivos, metodológicos e morais do trabalho dos CEPs. In: Carneiro F (org). A moralidade dos atos científicos questões emergentes dos Comitês de Ética em Pesquisa. Rio de Janeiro. Fiocruz, 1999.
7. Bussab WO, Morettin PA. Estatística básica. $5^{\text {a }}$ ed. São Paulo: Saraiva; 2006

8. Burke GS. Looking into the Institutional Review Board: observations from both sides of the table. J Nutr. 2005; 135:921-4.

9. Benatar SR. Reflections and recommendations on research ethics in developing countries. Social Sci \& Med. 2002;54:1131-41.

10. Coleman $\mathrm{CH}$, Bouësseau MC. How do we know that research ethics committees are really working? The neglected role of outcomes assessment in research ethics review. BMC Med Ethics. 2008;28;9:6.

11. Scmitz EF, Cunha DJD, Goldim JR. Índices de legibilidade em termos de consentimento informado de projetos de pesquisa do Hospital das Clínicas de Porto Alegre. Disponível em: <http://www.bioetica.ufrgs. br/legi899.htm>. [Acesso em 7 jul. 2008].

12. Francisconi CF, Bulla MC, Benincasa C, Teixeira R, Goldim JR. Índice de legibilidade dos termos de consentimento informado, utilizados em procedimentos assistenciais no HCPA. Disponível em: <http://www. bioetica.ufrgs.br/legiass.htm>. [Acesso em 7 jul. 2008]. 